\title{
Binary Logistic Regression Modeling of Idle CO Emissions in Order to Estimate Predictors Influences in Old Vehicle Park
}

\author{
Branimir Milosavljević, ${ }^{1}$ Radivoje Pešić, ${ }^{2}$ and Predrag Dašić ${ }^{1}$ \\ ${ }^{1}$ High Technical Mechanical School for Professional Studies, Radoja Krstića Street No. 19, 37240 Trstenik, Serbia \\ ${ }^{2}$ Department for Motor Vehicles and Motors, Faculty of Engineering, University of Kragujevac, Sestre Janjića Street No. 6, \\ 34000 Kragujevac, Serbia \\ Correspondence should be addressed to Predrag Dašić; dasicp58@gmail.com
}

Received 30 March 2015; Accepted 27 May 2015

Academic Editor: Mohammed Nouari

Copyright (C 2015 Branimir Milosavljević et al. This is an open access article distributed under the Creative Commons Attribution License, which permits unrestricted use, distribution, and reproduction in any medium, provided the original work is properly cited.

\begin{abstract}
This paper determines, by experiments, the $\mathrm{CO}$ emissions at idle running with 1,785 vehicles powered by spark ignition engine, in order to verify the correctness of emissions values with a representative sample of vehicles in Serbia. The permissible emissions limits were considered for three (3) fitted binary logistic regression (BLR) models, and the key reason for such analysis is finding the predictors that can have a crucial influence on the accuracy of the estimation whether such vehicles have correct emissions or not. Having summarized the research results, we found out that vehicles produced in Serbia (hereinafter referred to as "domestic vehicles") cause more pollution than imported cars (hereinafter referred to as "foreign vehicles"), although domestic vehicles are of lower average age and mileage. Another trend was observed: low-power vehicles and vehicles produced before 1992 are potentially more serious polluters.
\end{abstract}

\section{Introduction}

The emissions from a motor vehicle vary under different driving regimes [1]. One of the specific regimes is idle running, in which a vehicle may spend more than $25 \%$ of the operation time [2]. Testing of emissions at idle running was originally developed for vehicles that had very little or no emission control, which made it possible to detect the badly tuned and/or defective engines. Such vehicles are usually equipped with a mechanical carburetor or fuel injection system where the ratio of air-fuel mixture at idle running corresponds to the ratio of air-fuel mixture under load. Therefore, measurements of CO emissions at idle running (e.g., $2500 \mathrm{rpm}$ ) provide a reasonable indication of emissions under normal operating conditions for vehicles with a mechanical system of fuel supply control. Such vehicles include technologically old-fashioned automobiles that are used mainly in developing countries, such as the Republic of Serbia. Large proportion of total emissions from modern vehicles equipped with emission control system is caused by a small percentage of vehicles with a defective emission control system. The research carried out by Guensler [3] proved that 5\% of the vehicles cause up to $25 \%$ of total emissions, $15 \%$ of the vehicles cause up to $43 \%$ of emissions, and $20 \%$ of vehicles are responsible for $60 \%$ of emissions. If we want to consider emissions by type of harmful substances, Faiz et al. [4] demonstrated that $20 \%$ of vehicles cause $43 \%$ of the total CO emission.

The research indicated how the introduction of stricter limits of CO emissions at idle running is socially and politically acceptable [5]. CO idle concentrations were compared to international standards, and the tested vehicles were found to exhibit large failure rates, indicating the need of developing country-specific emissions standards. By measuring the actual distribution of emissions in the sample of Lebanese vehicles, the emissions standards were set so that a maximum of $20 \%$ of the vehicles would fail. Such failure rate would be considered socially and politically acceptable and is not 
expected to raise a significant public opposition to the program.

To identify the characteristics of vehicles that are significantly associated with emission test failures the most commonly used are multiple and logistic regression. Although in such cases the logistic regression is a more appropriate solution, in [6] multiple regression is used, which showed that engine size and type, age, and manufacturer significantly affect amounts of emissions. Larger-size engines emit smaller amounts of emissions, whereas older engines emit greater amounts.

However, the results and conclusions of the influence of vehicle characteristics using the logistic regression analysis are divided. Thus, for example, in [7] it was identified that a vehicle age or model year, except for the latest model catalyst-equipped vehicles, has little influence on emissions performance. On the other hand, the results of the study in [8] indicate that a vehicle age, vehicle manufacturer, number of engine cylinders, odometer reading, and whether or not oxygenated fuels were in use all play a significant role in determining the emissions test results and these statistical findings can be used to selectively target those vehicles most likely to cause high rate of air pollution. Also, the research in [9] used nearly 4 million records of data to estimate logit models of test failures and regression models of vehicle emissions. The vehicle age, fuel economy, mileage, engine characteristics, weight, make, general maintenance, and the seasons also are found to be strong determinants of emissions and test failure rates. Similarly more precise conclusions presented in paper [10] indicated that vehicles over 10 years old, engine size smaller than $2,000 \mathrm{cc}$, and odometer readings over $100,000 \mathrm{~km}$ would substantially increase the likelihood of finding high polluting vehicles.

Unlike binomial logistic regression, in [11] a new multinomial logit model is developed to identify the factors that are significantly associated with identified failed and gross polluting vehicles. The results are similar and also indicate that factors such as odometer reading, model year, and the vehicle make, along with the presence of modern emission control systems, are significant factors in predicting the likelihood being labeled as a failed vehicle and a gross polluter.

However, none of these studies provided the answer to the issue of how the influence of the abovementioned vehicle characteristics changes by the introduction of stricter emissions limits. The answer to this question can be provided by this research. In $[12,13]$ the choice of using the relevant logistic method in data analysis is discussed. In [14-16] variables in logistic regression models for ordinal and binary data calculations are shown. In [17-20] relationships between engine characteristic and emissions in urban and rural environments are analyzed.

The main reason for this study is the fact that the average age of vehicles in the Republic of Serbia (2011) is 17.5 years (Ministry of Internal Affairs of the Republic of Serbia, 2011). By identifying the dominant predictors which have impact on the resident $\mathrm{CO}$ emissions, as well as acting on them, we can create a possibility of early establishment of stricter emission standards and thus also a better protection of the environment and human health. The following sections describe the experiment and the methodology by which the obtained results were processed.

\section{Method and Equipment for Emission Measurement}

The experiment including measurements of $\mathrm{CO}$ emissions from passenger cars with spark ignition engine was carried out at 13 measuring points in the city of Kragujevac and technical inspection was carried out at Auto Moto Club Trstenik during 2008. The methodology of procedure is harmonized with the following EU directives: Council Directive 92/55/EEC and Council Directive 72/306/EEC. The emission was tested by AVL DiCom, a combined device for analyzing emissions and diagnostics of spark ignition engines and diesel engines (analyzer of 5 gases from spark ignition engines and opacimeter for diesel engines). The experimental base consists of 754 domestic and 1,031 foreign vehicles.

\section{Methodology of Results Processing}

The goal of the binary logistic regression (BLR) analysis is to find the model that is best adapted to the data but is still an acceptable model that describes the relationship between the dependent variable and a set of independent ones describing it. The dependent variable is usually marked $Y$ and independent one $X$. The probability $\pi$ of occurrence of one of the binary events $(Y=l), l=0,1$, for the case with several independent variables $\left(x_{i}\right), i=1,2, \ldots, m$, can be presented in the following form [21-23]:

$$
\begin{aligned}
\pi & =P\left(Y=1 \mid X_{1}=x_{1}, \ldots, X_{m}=x_{m}\right) \\
& =\frac{e^{\beta_{0}+\beta_{1} x_{1}+\beta_{2} x_{2}+\cdots+\beta_{m} x_{m}}}{1+e^{\beta_{0}+\beta_{1} x_{1}+\beta_{2} x_{2}+\cdots+\beta_{m} x_{m}}},
\end{aligned}
$$

where $\beta_{i}, i=0,1, \ldots, m$, are logistic regression coefficients.

Pearson $\chi^{2}$ statistics of residuals and their deviation may constitute a quality measure of rating compliance of the model with the output results. However, a problem occurs when $J \approx n$ (the number of unique experiments, i.e., the covariate patterns equal or approximately equal to the number of experiments) because the obtained $p$ values and used $\chi_{J-p-1}^{2}$ distribution are incorrect [22]. Since in this experiment $J \approx n$ $(1771 \approx 1785)$, we will describe briefly the statistics that will help us avoid the abovementioned problems, that is, Hosmer and Lemeshow goodness of fit (HL-GOF) statistics [24, 25].

Hosmer and Lemeshow showed that, for $J=n$ (as well as $J \approx n)$ and when the fitted logistic model is the correct model, the distribution of $H L-G O F$ statistics $(\widehat{C})$ approximates well with the $\chi_{g-2}^{2}$ distribution. Given that in this case we used the grouping method based on percentiles of the estimated probabilities (because many of the estimated probabilities are less than 0.2) HL-GOF statistics usually take $g=10$ groups. These groups are often referred to as the "deciles of risk." Also, it is believed that the model agrees well with the data if the $p$ value of the corresponding $\chi_{g-2}^{2}$ statistics is greater than 0.05 [22]. 
The permissible limits for a vehicle to pass the emission test were considered for 3 BLR models, with the engine at idle running and high number of revolutions $(2,500 \mathrm{rpm})$. The first model adopts the strictest standard or limits for $\mathrm{CO}$ in the state of Oregon (USA model) ( $\leq 1.0 \%$ vol CO). The second model adopts the limits specified in Article 82 of the Rules of the Division and the Technical Conditions of Motor Vehicles in Traffic of 26.04.2012, which stipulates that the vehicles registered for the first time in the Republic of Serbia before March 1st, 2014, have to emit less than $4.5 \%$ vol $\mathrm{CO}$, at engine speeds at operating temperature and idle running (SRB model). However, since the Republic of Serbia is a candidate for membership in the European Union (EU), the abovementioned rules comply with EU directives for vehicles registered for the first time after March 1st, 2014. Therefore, the third model will adopt its regulations (EU model) $(92 / 55 /$ ECC: vehicles with carburetor: $\leq 3.5$ and with injection: $\leq 0.3 \%$ vol CO).

The methodology applied for estimation of the cumulative and absolute frequency of the tested vehicles is given in [26-28] in which the algorithm approach and software for the selected distribution that best approximates the experimental data are described.

The following paragraphs present the calculation methodology of SRB, USA, and the EU BLR models.

The final models had to meet the following requirements:

(i) Independent variables have a significant impact on the dependent variable, if their Rao's score statistics are significant, that is, when it is tested by $\chi^{2}$ distribution with one degree of freedom, and at the same time the required $p$ value being equal or less than 0.05 is satisfied [29].

(ii) The lower the $-2 L L$ value, that is, -2 log likelihood value, of the new model $(-2 L L(\theta))$, the better the fit of the BLR model [30]. Logistic regression measures model estimation fit with the value of -2 times the log of the likelihood value, referred to as $-2 L L$.

(iii) The model is statistically significant if the difference of the credibility logarithms of the new $(L(\theta))$ and the base model $(L(0))$ is such that $p$ value being equal or less than 0.05 is satisfied when it is tested by $\chi^{2}$ distribution with $k+1-n$ degree of freedom $(k$, number of individual effects of the new model $L(\theta)$; $n$, number of parameters in the base model $L(0)$ which is always one, since the constant is the only parameter to be estimated) [31]. That is, we have to check whether the model with the sample is good enough to apply to the whole population (Omnibus test).

(iv) In assessing the significance of the coefficients of independent predictors (and their subcategories) using Wald's test, all these have to be significantly different from 0 , that is, to be tested by $\chi^{2}$ distribution. The condition is satisfied for $p$ value being equal or less than 0.05 [23].

(v) If $H L-G O F$ statistics show a good agreement of the model with the data, $p$ value of appropriate $\chi_{g-2}^{2}$ statistics must be greater than 0.05 (g: "deciles of risk," and they cannot exceed 10) [22].

After satisfactory combinations of the predictors have been selected, these predictors have to be ranked so that the predictors' group, for which \% of correct classification (Percentage Analyses, PA) [32] is the largest and the coefficient of the Nagelkerke determination $\left(R_{N}^{2}\right)$ [33] is the highest, constitute the group with the highest impact on the probability results of the dependent variable $Y$ in which a vehicle failed the $\mathrm{CO}$ emissions test (i.e., $P(Y=1)$ ).

The rate of the individual impacts of independent variables in the group will be evaluated according to the following criteria.

Criteria I. The higher the Wald's statistics value of the predictor, i.e. the higher the value of the relationship between a predictor's logistics regression coefficient and its standard error, the greater the probability that its (predictor) impact is significant.

Criteria II. The further odds ratio of the independent variable from 1 is, the greater the predictor's impact is [31].

Criteria III. The area under the curve (AUC) essentially assesses the quality of predictors in the established model, whose calculation requires the plotting of ROC curve [23]. ROC stands for Receiver Operating Characteristic and when applied to a logistic model, an ROC is a plot of sensitivity (Se) (Se, the proportion of true positives among all cases) versus 1 - specificity $(1-S p)$ (Sp, the proportion of true negatives among all noncases) derived from several cut-points for the predicted value. It is necessary to emphasize that, for a given cut-point, the closer both the sensitivity and specificity are to 1 , the better the discriminatory performance [22].

\section{Results and Discussion}

When setting a BLR model, the first thing you have to do is to select those variables (predictors) that you believe, based on your intuition or experience, can affect the test results. Table 1 presents the contingency table, that is, the results of the Pearson correlation coefficient $(R)$ between all the assumed predictors affecting the results of the abovementioned emissions test.

The contingency table clearly shows highly significant correlation between the engine power and displacement, so one of them has to be eliminated as a potential model predictor. The reason is that if we adopt predictors which are strongly correlated, they will be in constant collision in the model; that is, they will share the variance and cause errors in the output results. Due to the lower standard deviation $\left(\mathrm{SD}_{\mathrm{EP}}=20 ; \mathrm{SD}_{\mathrm{ED}}=305\right)$ and standard error $\left(\mathrm{SE}_{\mathrm{EP}}=0.4\right.$; $\mathrm{SE}_{\mathrm{ED}}=8.1$ ) of engine power compared to its displacement, the second enumerated predictor is eliminated as a possible predictor of the model. Another reason for the rejection is the conditions imposed on by the BLR, which require that the minimum number of samples should be at least 400 [23]. In order to provide the model accuracy, every single subcategory 
TABLE 1: Contingency table of presumed predictors that can affect the $\mathrm{CO}$ emissions test results.

\begin{tabular}{|c|c|c|c|c|c|c|c|}
\hline Symbol of predictor & TA & OR & VA & ED & EP & SFS & $\mathrm{K}$ \\
\hline TA & 1 & $-0.413^{\mathrm{a}}$ & $0.074^{\mathrm{a}}$ & $-0.767^{\mathrm{a}}$ & $-0.703^{\mathrm{a}}$ & $0.590^{\mathrm{a}}$ & $0.557^{\mathrm{a}}$ \\
\hline OR & & 1 & $0.512^{\mathrm{a}}$ & $0.511^{\mathrm{a}}$ & $0.451^{\mathrm{a}}$ & $-0.129^{a}$ & $0.022^{\mathrm{a}}$ \\
\hline VA & & & 1 & $-0.049^{b}$ & $-0.140^{\mathrm{b}}$ & $0.427^{\mathrm{a}}$ & $0.519^{\mathrm{a}}$ \\
\hline $\mathrm{ED}$ & & & & 1 & $0.899^{\mathrm{a}}$ & $-0.594^{\mathrm{a}}$ & $-0.461^{\mathrm{a}}$ \\
\hline $\mathrm{EP}$ & & & & & 1 & $-0.615^{\mathrm{a}}$ & $-0.475^{\mathrm{a}}$ \\
\hline SFS & & & & & & 1 & $0.792^{\mathrm{a}}$ \\
\hline $\mathrm{K}$ & & & & & & & 1 \\
\hline
\end{tabular}

Notes: ${ }^{\mathrm{a}} p$ value $\leq 0.01 ;{ }^{\mathrm{b}} p$ value $\leq 0.05$; TA: territorial affiliation; OR: odometer readings; VA: Vehicle age; ED: engine displacement; EP: engine power; SFS: system of fuel supply; K: catalytic converter (CAT).

TABLE 2: Adopted predictor for BLR modeling.

\begin{tabular}{|c|c|c|c|c|}
\hline Symbol of predictor & Mark of logistic predictor $\left(x_{i}, i=1, \ldots, 6\right)$ & Definition of predictor & Type of predictor & Dummy coding \\
\hline \multirow{2}{*}{ TA } & \multirow{2}{*}{ 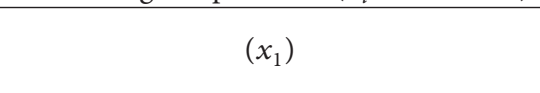 } & \multirow{2}{*}{ Territorial Affiliation } & \multirow{2}{*}{ (bi)nominal } & $0\left(\right.$ foreign $\left.^{\mathrm{a}}\right)$ \\
\hline & & & & 1 (domestic) \\
\hline OR & $\left(x_{2}\right)$ & Odometer Readings & Discrete & Scale \\
\hline VA & $\left(x_{3}\right)$ & Vehicle age & Discrete & Scale \\
\hline \multirow{3}{*}{ EP } & \multirow{3}{*}{$\left(x_{4}\right)$} & \multirow{3}{*}{ Engine power } & \multirow{3}{*}{ Categorical interval } & $0(\leq 40 \mathrm{~kW})^{\mathrm{a}}$ \\
\hline & & & & $1(41-70 \mathrm{~kW})$ \\
\hline & & & & $2(\geq 71 \mathrm{~kW})$ \\
\hline \multirow{2}{*}{ SFS } & \multirow{2}{*}{$\left(x_{5}\right)$} & \multirow{2}{*}{ System of fuel supply } & \multirow{2}{*}{ (bi)nominal } & 0 (injection) \\
\hline & & & & 1 (carburetor) \\
\hline \multirow[t]{2}{*}{$\mathrm{K}$} & \multirow{2}{*}{$\left(x_{6}\right)$} & \multirow{2}{*}{ Catalytic converter (CAT) } & \multirow{2}{*}{ (bi)nominal } & 0 (with $\mathrm{CAT}^{\mathrm{a}}$ ) \\
\hline & & & & 1 (no CAT) \\
\hline
\end{tabular}

Notes: ${ }^{a}$ reference subcategory in related category.

of the potential independent variable needs to fulfill the requirements, which is not achieved with the division of predictor ED. Table 2 presents the adopted predictors of BLR starting model.

The subcategory of engine power up to $40 \mathrm{~kW}$ is of similar average age with both domestic and foreign vehicles, and since the abovementioned category rises, the average age and consequently the average mileage are higher with foreign vehicles. Foreign vehicles with carburetors are on average older by 3 years and with the injection system by 9 years than domestic vehicles. Also, foreign vehicles have the average mileage greater by $84 \%$. In addition, $45 \%$ of the sampled foreign vehicles do not have a catalyst, and $41 \%$ of them do not have a modern system of fuel supply. Figure 1 shows threedimensional (3D) plot diagram dependency of the other two predictors (OR and VA) with CO emission results at $z$ axis.

Figure 1 unambiguously demonstrates that foreign vehicles have lower average emissions so we can deduct that domestic vehicles cause more pollution than foreign vehicles. This is confirmed by the mean value of $\mathrm{CO}$ emissions $\left(\bar{x}_{\text {domestic }}=3,6 ; \bar{x}_{\text {foreign }}=1,99\right)$. One of the reasons is that $97 \%$ of the sampled domestic vehicles have a carburetor and no CAT.

Figure 2(a) shows the number of vehicles that meet the emissions standards. If we used the SRB emission model, $85 \%$ of vehicles would meet the required norms, but if we adopt the strictest emission limit (USA model), the number

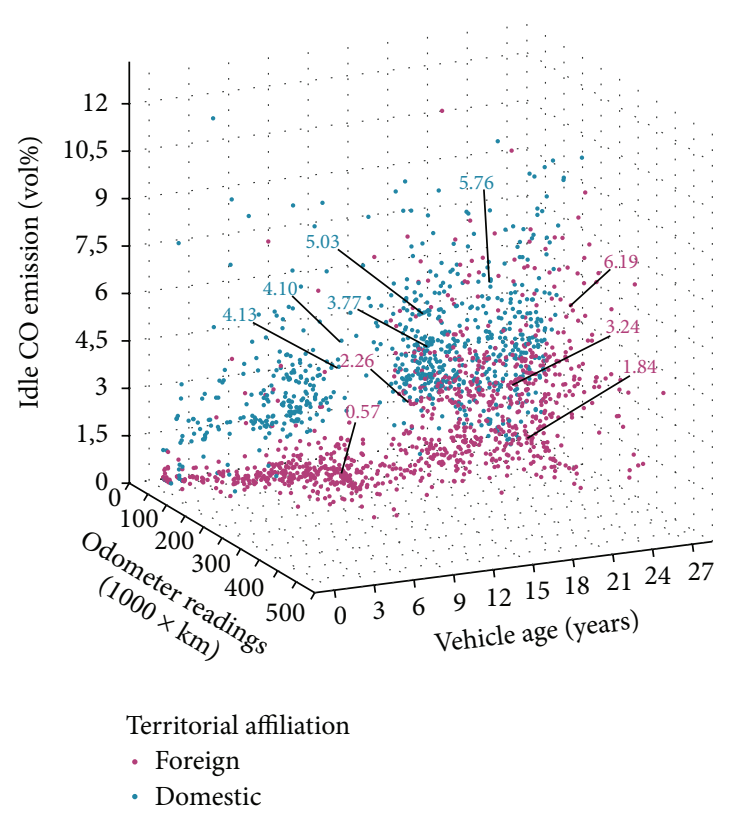

FIgURE 1: 3D plot diagram of dependency between predictors. OR and VA with the results of $\mathrm{CO}$ emissions at idle running.

of such vehicles decreases to only $25 \%$ of the sampled vehicles. Thus, adoption of the emission standards stricter by 4.5 times 
TABLE 3: Fitted BLR models according to the defined requirements.

\begin{tabular}{|c|c|c|c|c|c|c|}
\hline Model & Predictors & $-2 L L(\theta)$ & $\chi_{(\mathrm{df}=k+1-n)}^{2}$ & PA [\%] & $R_{N}^{2}$ & $\chi_{g-2}^{2}(\mathrm{df})$ \\
\hline SRB & $x_{3} x_{4} x_{5} x_{6}$ & 1194.8 & $304.6(5)^{a}$ & 85.2 & 0.28 & $11.947(8)^{b}$ \\
\hline $\mathrm{EU}$ & $x_{2} x_{4} x_{5} x_{6}$ & 1836.8 & $612.1(5)^{\mathrm{a}}$ & 74.6 & 0.39 & $11.534(8)^{b}$ \\
\hline USA & $x_{2} x_{3} x_{4} x_{5} x_{6}$ & 174.2 & $1805.8(6)^{\mathrm{a}}$ & 97.3 & 0.95 & $1.364(8)^{b}$ \\
\hline
\end{tabular}

Notes: ${ }^{\mathrm{a}} p$ value $\leq 0.01 ;{ }^{\mathrm{b}} p$ value $>0.05$; df: degree of freedom; $R_{N}^{2}$ : Nagelkerke determination coefficient; $-2 L L(\theta)$ : $\log$ likelihood of the new model.

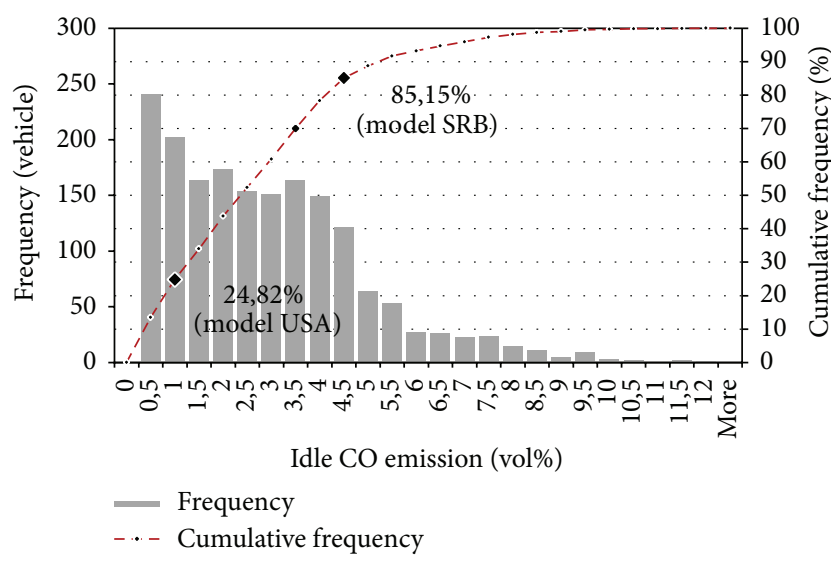

(a)

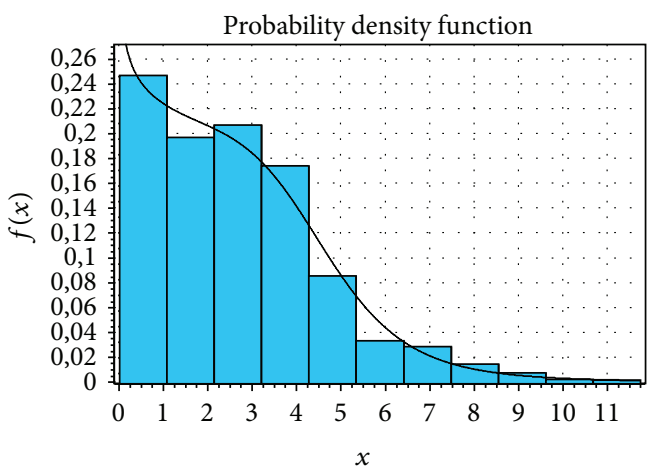

( Histogram-Dagum

(b)

FIGURE 2: Cumulative and absolute frequency of tested vehicles (a) and probability density function (PDF) (b).

results in further increase of the number of vehicles with improper emissions by $60 \%$. The EU emission limits are met by $44 \%$ of vehicles.

The adequacy of the null hypothesis $H_{o}: X \sim \operatorname{Dagum}(a$; $b ; p)$ is tested by using $\lambda$-Kolmogorov test for the adopted probability of $P=0.95$ (Figure 2(b)). The critical value $(D)$ can be estimated as $D=\lambda(P) / \sqrt{n}=0.03219$. Since the condition is satisfied, $\sup _{x}\left|F_{n}(x)-F(x)\right|=0.02916 \leq D$, we can accept the null hypothesis, $H_{o}: X \sim \operatorname{Dagum}(5.088$; 5.046; 0.176 ), that the probability density function of the Dagum distribution (Type I) best approximates the experimental data ( $p$ value is 0.09423 ).

Calculated Rao's score statistics of univariable (i.e., with single independent variable) logistic regression with all the three models proves that all predictors have an impact on model results, except for the predictor OR in the model SRB (the value of the score statistic is 2.55 and it is not significant, because $p$ value of tested $\chi_{1}^{2}$ distribution is 0.1111 ). Therefore we will not take into account the predictor OR as the one which can possibly affect the results in the model SRB. The results in Table 3 were obtained by selecting the combinations of the set of predictors and their classification and ranking according to the predefined requirements.

It is necessary to emphasize that we will not evaluate the models that contain joint impact of two or more predictors but we will evaluate only those models that include the individual predictor's effects.
The probability calculation of the vehicle failing the $\mathrm{CO}$ emissions test for SRB, EU, and USA model can be expressed in the form

$$
\begin{aligned}
& P_{\mathrm{SRB}}\left(Y=1 \mid X_{i}=x_{i}\right) \\
& =\frac{e^{(-7.28+0.077 \mathrm{VA}-0.77 \mathrm{EP}(1)-1.14 \mathrm{EP}(2)+1.94 \mathrm{SFS}(1)+2.94 \mathrm{~K}(1))}}{1+e^{(-7.28+0.077 \mathrm{VA}-0.77 \mathrm{EP}(1)-01.14 \mathrm{EP}(2)+1.94 \mathrm{SFS}(1)+2.94 \mathrm{~K}(1))}} \\
& P_{\mathrm{EU}}\left(Y=1 \mid X_{i}=x_{i}\right) \\
& =\frac{e^{(1.08+0.000017 \mathrm{OR}-1.64 \mathrm{EP}(1)-2.32 \mathrm{EP}(2)-7.11 \mathrm{SFS}(1)+4.50 \mathrm{~K}(1))}}{1+e^{(1.08+0.000017 \mathrm{OR}-1.64 \mathrm{EP}(1)-2.32 \mathrm{EP}(2)-7.11 \mathrm{SFS}(1)+4.50 \mathrm{~K}(1))}} \\
& P_{\mathrm{USA}}\left(Y=1 \mid X_{i}=x_{i}\right) \\
& =\frac{e^{(-10.61+0.000045 \mathrm{OR}+0.59 \mathrm{VA}-6.44 \mathrm{EP}(1)-8.53 \mathrm{EP}(2)+9.5 \mathrm{SFS}(1)+6.41 \mathrm{~K}(1))}}{1+e^{(-10.61+0.000045 \mathrm{OR}+0.59 \mathrm{VA}-6.44 \mathrm{EP}(1)-8.53 \mathrm{EP}(2)+9.5 \mathrm{SFS}(1)+6.41 \mathrm{~K}(1))}}
\end{aligned}
$$

In Table 4, column 3 contains the logistic regression coefficients and column 4 contains their standard error, while the last column contains odds ratio, that is, logistic regression coefficient exponent of the considered predictor.

Now that all predictors of the fitted SRB, EU, and the USA models are identified, the significance of individual impacts has to be assessed. If we use the SRB model to analyze the impact of independent variables through the ratio between Wald's statistics and the standard error of the predictor logistic regression coefficient, we obtain the result that the vehicle age is the greatest. Since it is a discrete type of predictor, it is 
TABLE 4: Logistic estimates for CO emission test failure.

\begin{tabular}{|c|c|c|c|c|c|}
\hline Model & Predictors & $\beta_{i}$ & $\mathrm{SE}_{\beta_{i}}$ & Wald statistics (df) & $e^{\beta_{i}}$ \\
\hline \multirow{5}{*}{ SRB } & VA & 0.077 & 0.014 & $31.08(1)^{\mathrm{a}}$ & 1.080 \\
\hline & $\mathrm{EP}(1)$ & -0.766 & 0.173 & $19.580(1)^{\mathrm{a}}$ & 0.465 \\
\hline & $\mathrm{EP}(2)$ & -1.14 & 0.29 & $15.453(1)^{\mathrm{b}}$ & 0.319 \\
\hline & SFS(1) & 1.938 & 0.585 & $10.961(1)^{\mathrm{a}}$ & 6.944 \\
\hline & $\mathrm{K}(1)$ & 2.943 & 1.042 & $7.969(1)^{\mathrm{b}}$ & 18.969 \\
\hline \multirow{5}{*}{$\mathrm{EU}$} & OR & 0.000017 & 0.000001 & $217.803(1)^{\mathrm{a}}$ & 1.000017 \\
\hline & $\mathrm{EP}(1)$ & -1.636 & 0.157 & $108.538(1)^{\mathrm{a}}$ & 0.195 \\
\hline & $\mathrm{EP}(2)$ & -2.319 & 0.24 & $93.342(1)^{\mathrm{a}}$ & 0.098 \\
\hline & SFS(1) & -7.106 & 1.05 & $45.829(1)^{\mathrm{a}}$ & 0.00082 \\
\hline & $\mathrm{K}(1)$ & 4.502 & 1.031 & $19.067(1)^{\mathrm{a}}$ & 90.181 \\
\hline \multirow{6}{*}{ USA } & OR & 0.000045 & 0.000006 & $56.939(1)^{\mathrm{a}}$ & 1.000045 \\
\hline & VA & 0.597 & 0.078 & $59.413(1)^{\mathrm{a}}$ & 1.822 \\
\hline & $\mathrm{EP}(1)$ & -6.436 & 0.98 & $43.167(1)^{\mathrm{a}}$ & 0.001603 \\
\hline & $\mathrm{EP}(2)$ & -8.525 & 1.166 & $53.485(1)^{\mathrm{a}}$ & 0.000199 \\
\hline & $\operatorname{SFS}(1)$ & 9.5 & 1.366 & $48.339(1)^{\mathrm{a}}$ & $1,3360.72$ \\
\hline & $\mathrm{K}(1)$ & 6.41 & 1.246 & $26.483(1)^{\mathrm{a}}$ & 608.141 \\
\hline
\end{tabular}

Notes: ${ }^{\mathrm{a}} p$ value $\leq 0.01 ;{ }^{\mathrm{b}} p$ value $\leq 0.05$; df: degree of freedom; $\mathrm{EP}(1)$ : first subcategory in category of engine power $(41-70 \mathrm{~kW})$; $\mathrm{EP}(2)$ : second subcategory in the category of engine power (>71 kW); SFS(1): first subcategory in category of the system of fuel supply (vehicles with carburetor); K(1): first subcategory in the category of the catalytic converter (CAT) (vehicles without CAT).

necessary to calculate the odds of test failure for a 10 - or 20 year-old vehicle. If the vehicle is older by 1 year, the odds of failure increase by 1.08 times. If the vehicle is older by 10 years, the odds increase by 2.15 times, while in case of a vehicle older by 20 years the odds of failure increase by 4.7 times. If we want to find out $\%$ of increase in the probability of failing the test with vehicles 5-, 10-, or 20-year old, it is necessary to obtain a new odds value as a product of the old odds value, the odds ratio value, and the change in the independent variable [30]. Thus, a 5-year-old vehicle has the increase of the probability of test failure by additional $31 \%$, a 10 -year-old vehicle by $41 \%$, and a 20 -year-old vehicle by $45 \%$.

The exponent of the logistic regression coefficient represents the change of the odds resulting from the change of the predictor variable by one unit. Therefore, increasing the age of vehicle by 1 year, the odds of the vehicle failing the test increase by $8 \%$, while for the USA model the increase would be $82.2 \%$. Applying the emissions standard stricter by 4.5 times would result in the increase of odds of the emissions test failure by $\sim 10$ times with only one-year increase of age.

Based on the relation between Wald's statistics and the standard error of the logistic coefficient of predictors, the total mileage covered by a vehicle occurs as the most influential predictor in the models of the EU and the USA. The explanation that a vehicle has odds of emissions test failure greater by 1.000017 times after it covers only $1 \mathrm{~km}$ more is unreasonable. It would be more realistic to take into account how much the change of odds would increase after the vehicle covers additional 5000, 10000, 50000, or $100000 \mathrm{~km}$. Table 5 provides the required answer.

From Table 5 described, it is possible to deduct that, by applying the EU model, which has been in force since March 1,2014 , the sampled vehicles used in Serbia have 5.47 times greater odds of emissions test failure having covered each
TABLE 5: Odds failure changings of predictor OR.

\begin{tabular}{lcc}
\hline Additional distance covered $[\mathrm{km}]$ & EU model & USA model \\
\hline 5,000 & 1.09 & 1.25 \\
10,000 & 1.18 & 1.57 \\
50,000 & 2.34 & 9.49 \\
100,000 & 5.47 & 90 \\
\hline
\end{tabular}

$100,000 \mathrm{~km}$, while the adoption of stricter emission norms (USA) would increase the odds of failing by 90 times or 9.5 times for each $50,000 \mathrm{~km}$ covered.

Comparing the first two tests of influence of the predictors in Table 4, we can see that there is a significant divergence in the results, so it is necessary to consider the third criterion as well. However, before we do that by using ROC curve, we will analyze the only predictor of the category with more than two subcategories, the engine power.

Reference subcategory comprises engines up to $40 \mathrm{~kW}$ (Table 2). The coefficient exponent of subcategory 1 (0.465) and subcategory 2 (0.319) in model SRB (Table 4 ) is the odds ratio of a vehicle failing emissions test compared to reference subcategory. Since these values are lower than 1 , it is necessary to observe the inverse proportional relationship; that is, 1 is to be divided by the obtained/resulting coefficient exponent (odds ratio value lower than 1 reduces the probability of the vehicle having failed the test; i.e., it increases the probability of the vehicle having correct emissions values). Thus, in the SRB model, the engines in subcategory 1 have 2.15 times greater odds of fulfilling emission standards than the engines in reference subcategory, while the engines in subcategory 2 have 3.13 times greater odds to fulfill the emissions standards. Since this predictor is applied in all 3 models, Table 6 shows the analytically summarized relations. It clearly indicates that 
TABLE 6: Odds relation analysis of emission test pass compared to reference subcategory of predictor EP.

\begin{tabular}{lccc}
\hline $\begin{array}{l}\text { Subcategory of } \\
\text { predictor EP }\end{array}$ & SRB model & EU model & USA model \\
\hline $\mathrm{EP}(1)$ & 2.15 & 5.13 & 623 \\
$\mathrm{EP}(2)$ & 3.13 & 10.21 & 5,025 \\
\hline
\end{tabular}

the stricter the emission standards are, the greater the odds of high-power engines to have correct emission values are.

As already noted, disagreement between the first two criteria of the evaluation of predictors' impact is evident. The answer can be obtained by using a ROC curve. The area under the curve (AUC) provides the value that can be compared and placed within the defined boundaries of separating quality. The larger the area under the curve, the better the discrimination [22].

The AUC values for influential predictors of SRB model are VA (0.702), EP (0.306), SFS (0.698), and K (0.691). It is notable that only the predictor VA has acceptable separation, whereas variables SFS and $\mathrm{K}$ belong to a group with poor separation. For this reason, cut-point is determined (Figure 3), showing that the SRB model has acceptable separation on vehicles which have passed the test, compared to those that have not at the 19-year-old vehicle, and such event has $50 \%$ probability to occur. The predictor EP is far below the reference curve, but this can be explained by the abovementioned predictor having a greater impact on the assessment of vehicles that can pass the test, that is, which have correct emissions. That is why we can claim that, in the SRB model, variable VA constitutes the highest quality predictor of accuracy of whether the vehicle has failed the emission test.

The AUC values of the influential predictors of the EU model are OR (0.711), EP (0.568), SFS (0.350), and K (0.424). Predictor OR has acceptable separation, while EP belongs to a group with poor separation. For this reason, the cut-point is determined (Figure 3), which shows that the EU model has the most accurate separation of the vehicles that have passed the test compared to those that have not when they have covered $110,000 \mathrm{~km}$. In the conclusion, the predictor OR is the highest quality variable of output results accuracy assessment if the vehicle failed the emission test.

Figure 3 shows the results of the USA model and the AUC values for influential predictors of the USA model are OR (0.623), VA (0.890), EP (0.222), SFS (0.919), and K (0.936). Considering the AUC value, the predictors, SFS and $\mathrm{K}$, have exceptional separation of correct answers from the incorrect ones, while the independent variable VA, now in the USA model compared to SRB model, in the estimation of the correct answers goes up by one level in the separation quality scale, and now is in the group that performs excellent separation. The total mileage in the USA model does not constitute a quality indicator, whereas the predictor: fuel supply system makes it possible to make a better estimation which vehicle has passed the $\mathrm{CO}$ emissions test. The USA model has the most accurate separation to the vehicles that have passed the test from those that have not passed it at 11year-old vehicles. Thus, we can deduct that by introducing stricter emissions standards, the predictor VA improves its quality in terms of accuracy of properly graded vehicles that have failed the test.

If we compare the 3 quality assessment tests, that is, the significance of predictors in the model, we can perceive complete concordance between criteria I and III, which additionally assure us that a vehicle age is a very influential variable in case of extreme emissions limits, whereas the predictor OR is the most influential in case of moderate emissions limits (model EU).

Finally, we have to consider the probability results of a vehicle failing the emission test for the reference model SRB. Thereat, Figure 4 is first shown with the division in domestic and foreign vehicles and predictors VA and EP (Figures 4(a) and 4(b)).

It is obvious that domestic vehicles have a greater probability of failing the test than foreign vehicles. This also applies to vehicles of lower engine power, that is, lower displacement (since a strong correlation has been proven between the abovementioned predictors in Table 1).

Figure 4(c) shows the probability diagram of the model SRB, depending on the most influential predictor VA with the confidence interval of the case occurrence in $95 \%$ vehicles (population). It can be deducted from the figure that the sampled vehicles in Serbia demonstrate huge differences in the probability of emission test failure with cars in the age group 16 to 20 . Taking the average probability of the test failure of $9 \%$, the critical vehicle is 16 years old, and this probability would rise to $21 \%$ within next four years. The difference of $12 \%$ in only four years is a clear indication of rapid increase of number of vehicles with improper emissions, such vehicles being produced before 1992. It is indicated that since that year, most of the world's car manufacturers have been installing catalyzers in serial production, all in order to meet the new EURO1 emission standards.

\section{Conclusions}

One of the conclusions of the experimental studies of emissions test is that according to the current legislation, that is, the model SRB ( $\leq 4.5 \%$ vol CO), a vehicle age influences the most the probability of it failing the $\mathrm{CO}$ emission test. Domestic cars, although of lower average age and mileage, cause more pollution than foreign cars and are more likely to fail the test. Introduction of the emission standard stricter by 4.5 times would result in 10 times larger odds of the test failure with each additional year of age. With the current standard of the CO limits, it is satisfied by $85 \%$ of the 1,785 sampled vehicles in Serbia. However, if we applied one of the world's most demanding standards (the State of Oregon, USA), only $25 \%$ of the vehicles in use would pass the emissions test. This means that another $60 \%$ of vehicles would have incorrect emissions.

The results of this study can be used for defining the factors that contribute the most to increase of the number of vehicles with improper emissions and considering the change of impact of those factors depending on introducing stricter 

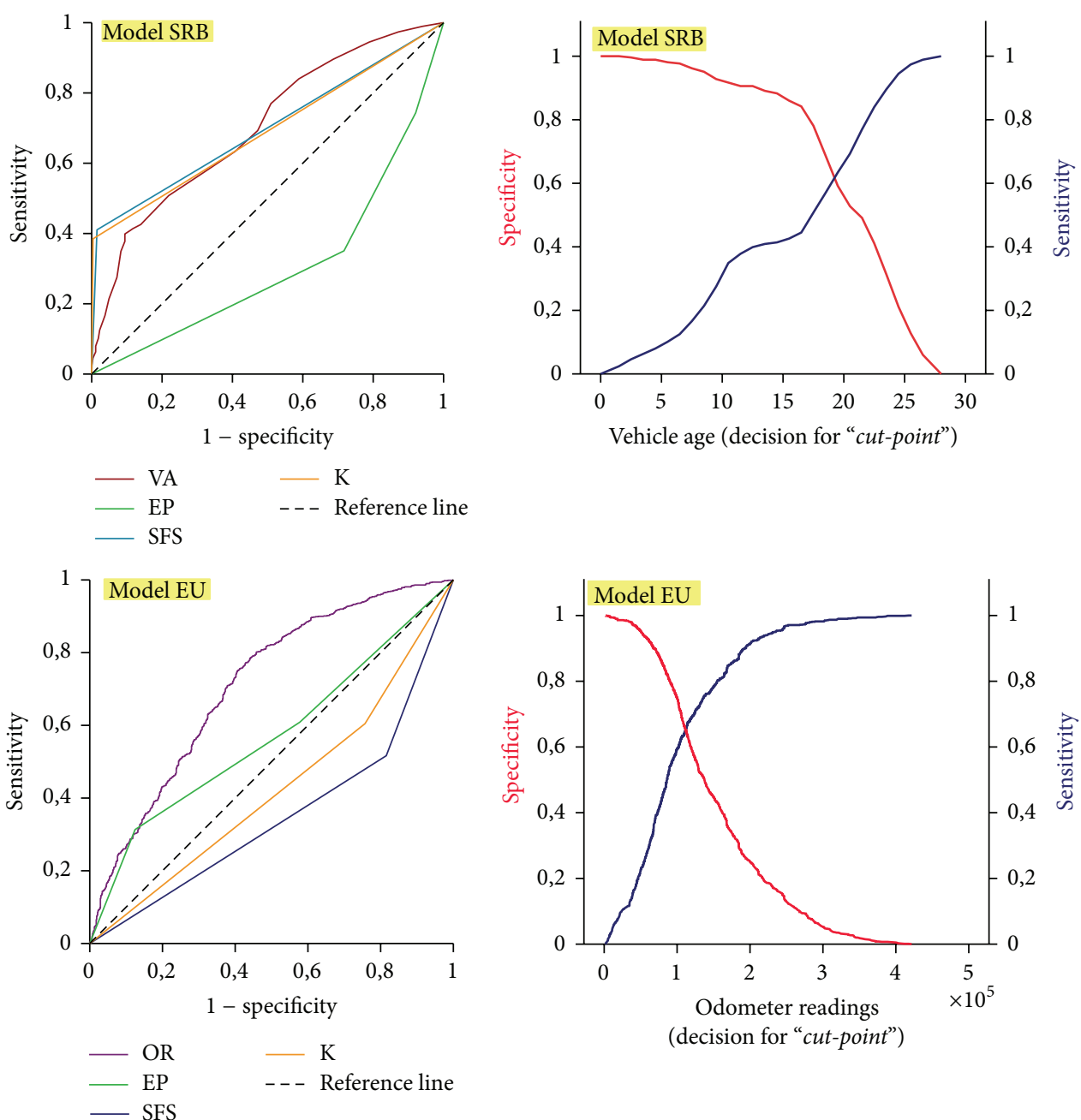

(decision for "cut-point")

SFS
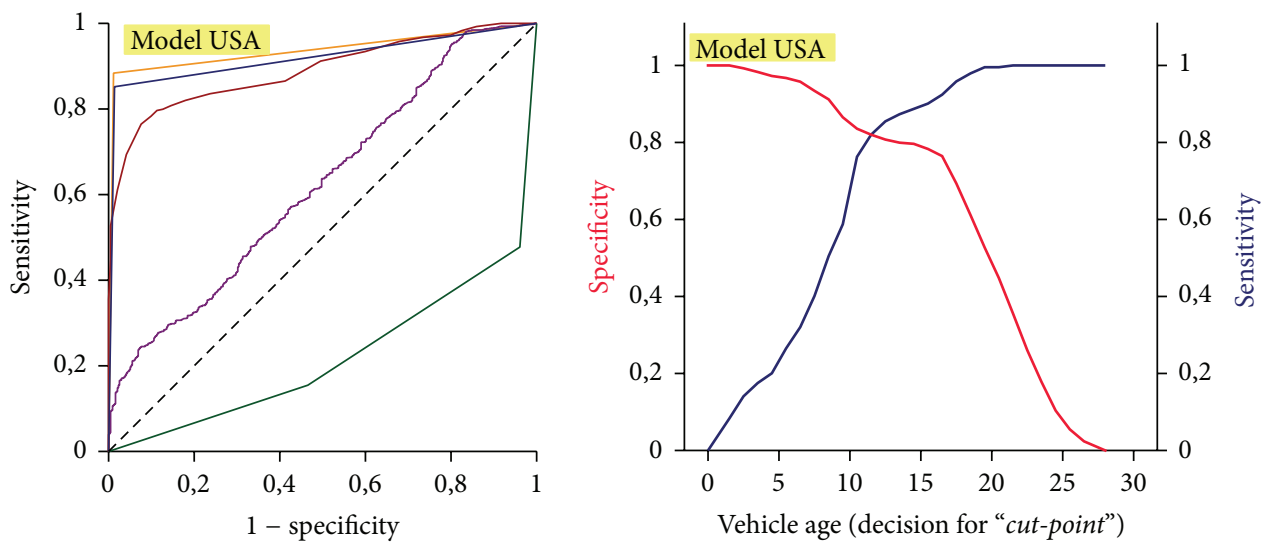

$$
\begin{array}{ll}
\text { OR } & - \text { SFS } \\
\text { VA } & - \text { K } \\
\text { EP } & --- \text { Reference line }
\end{array}
$$

FIGURE 3: ROC curve and "cut-point" of predictors OR and VA in the SRB, EU, and USA model. 


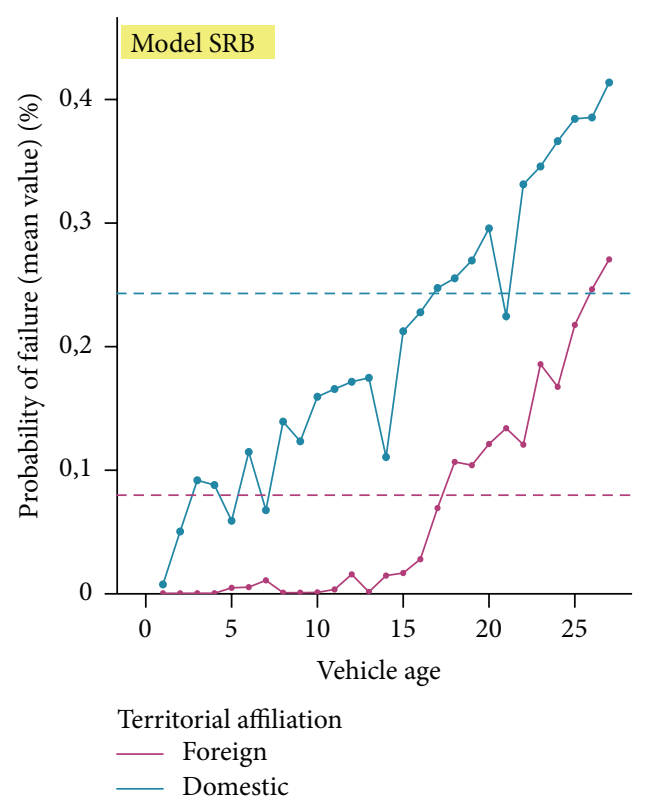

(a)

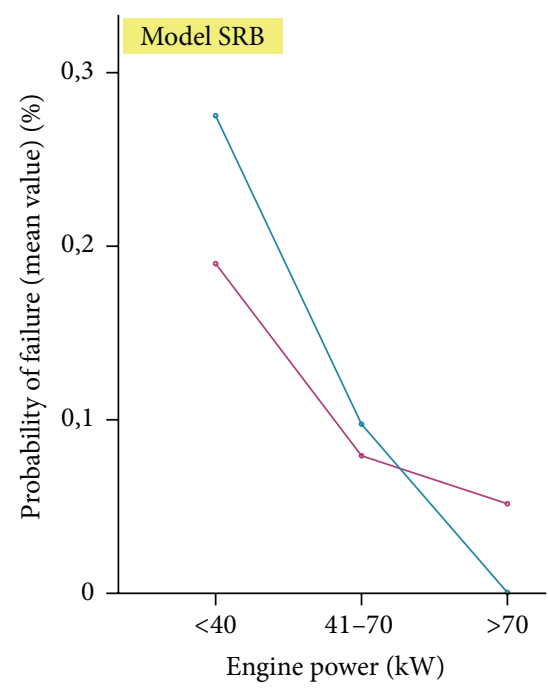

Territorial affiliation

— Foreign

(b)

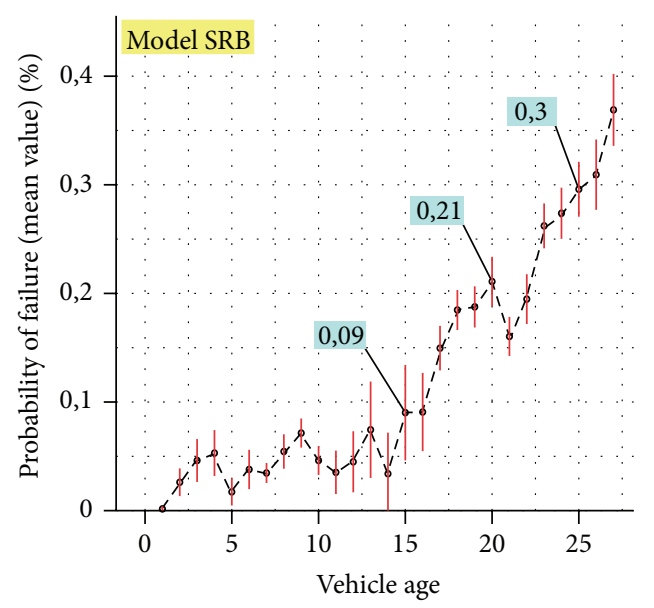

(c)

FIgURE 4: Actual CO emission test failure rates by predictors VA and EP in model SRB.

emission standards, but there are also some other practical uses. One of them is evaluating the possible incentives (reduction registration of vehicles taxes, etc.) owners to invest in the maintenance of their vehicles in order to reduce the negative environmental impact of each vehicle.

\section{Conflict of Interests}

The authors declare that there is no conflict of interests regarding the publication of this paper.

\section{Acknowledgment}

The paper is the result of the researches within the project TR 35041 that is supported by the Ministry of Education, Science and Technological Development of Serbia.

\section{References}

[1] H. C. Frey, A. Unal, N. M. Rouphail, and J. D. Colyar, “On-road measurement of vehicle tailpipe emissions using a portable instrument," Journal of the Air \& Waste Management Association, vol. 53, no. 8, pp. 992-1002, 2003.

[2] H. Y. Tong, W. T. Hung, and C. S. Cheung, "On-road motor vehicle emissions and fuel consumption in urban driving conditions," Journal of the Air \& Waste Management Association, vol. 50, no. 4, pp. 543-554, 2000.

[3] R. Guensler, Loop Holes for Air Pollution, ITS Review, University of California, Berkeley, Calif, USA, 1994.

[4] A. Faiz, C. S. Weaver, and M. P. Walsh, Air Pollution from Motor Vehicles: Standards and Technologies for Controlling Emissions, World Bank, Washington, DC, USA, 1996.

[5] M. Kazopoulo, M. El Fadel, and I. Kaysi, "Emission standards development for an inspection/maintenance program," Journal of Environmental Engineering, vol. 131, no. 9, pp. 1330-1339, 2005. 
[6] C.-W. Lin, S.-J. Lu, and K.-S. Lin, "Test emission characteristics of motorcycles in Central Taiwan," Science of the Total Environment, vol. 368, no. 2-3, pp. 435-443, 2006.

[7] A. Faiz, B. Bahadur Ale, and R. K. Nagarkoti, "The role of inspection and maintenance in controlling vehicular emissions in Kathmandu valley, Nepal," Atmospheric Environment, vol. 40, no. 31, pp. 5967-5975, 2006.

[8] S. Washburn, J. Seet, and F. Mannering, "Statistical modeling of vehicle emissions from inspection/maintenance testing data: an exploratory analysis," Transportation Research, Part D: Transport and Environment, vol. 6, no. 1, pp. 21-36, 2000.

[9] M. Beydoun and J.-M. Guldmann, "Vehicle characteristics and emissions: logit and regression analyses of $\mathrm{I} / \mathrm{M}$ data from Massachusetts, Maryland, and Illinois," Transportation Research Part D: Transport and Environment, vol. 11, no. 1, pp. 59-76, 2006.

[10] O. Bin, "A logit analysis of vehicle emissions using inspection and maintenance testing data," Transportation Research Part D: Transport and Environment, vol. 8, no. 3, pp. 215-227, 2003.

[11] S. Choo, K. Shafizadeh, and D. Niemeier, "The development of a prescreening model to identify failed and gross polluting vehicles," Transportation Research Part D: Transport and Environment, vol. 12, no. 3, pp. 208-218, 2007.

[12] S. J. Press and S. Wilson, "Choosing between logistic regression and discriminant analysis," Journal of the American Statistical Association, vol. 73, no. 364, pp. 699-705, 1978.

[13] H. Midi, S. K. Sarkar, and S. Rana, "Collinearity diagnostics of binary logistic regression model," Journal of Interdisciplinary Mathematics, vol. 13, no. 3, pp. 253-267, 2010.

[14] S. Menard, "Coefficients of determination for multiple logistic regression analysis," The American Statistician, vol. 54, no. 1, pp. 17-24, 2000.

[15] R. Kay and S. Little, "Transformations of the explanatory variables in the logistic regression model for binary data," Biometrika, vol. 74, no. 3, pp. 495-501, 1987.

[16] R. Bender and U. Grouven, "Using binary logistic regression models for ordinal data with non-proportional odds," Journal of Clinical Epidemiology, vol. 51, no. 10, pp. 809-816, 1998.

[17] W. Harrington, V. McConnell, and A. Ando, "Are vehicle emission inspection programs living up to expectations?" Transportation Research Part D: Transport and Environment, vol. 5, no. 3, pp. 153-172, 2000.

[18] K. S. Chen, W. C. Wang, H. M. Chen et al., "Motorcycle emissions and fuel consumption in urban and rural driving conditions," Science of the Total Environment, vol. 312, no. 1-3, pp. 113122, 2003.

[19] C. W. Lin, Y. R. Chen, S. J. Lu et al., "Relationships between characteristics of motorcycles and hydrocarbon emissions in Taiwan: a note," Transportation Research Part D: Transport and Environment, vol. 13, no. 5, pp. 351-354, 2008.

[20] S. Caserini, C. Pastorello, P. Gaifami, and L. Ntziachristos, "Impact of the dropping activity with vehicle age on air pollutant emissions," Atmospheric Pollution Research, vol. 4, no. 3, pp. 282-289, 2013.

[21] M. Pohar, M. Blas, and S. Turk, "Comparison of logistic regression and linear discriminant analysis: a simulation study," Metodološki Zvezki, vol. 1, no. 1, pp. 143-161, 2004.

[22] G. D. Kleinbaum and M. Klein, Logistic Regression: A Self Learning Text, Springer, New York, NY, USA, 3rd edition, 2010.

[23] W. D. Hosmer and S. Lemeshow, Applied Logistic Regression, John Wiley \& Sons, Hoboken, NJ, USA, 3rd edition, 2003.
[24] D. W. Hosmer and S. Lemeshow, "A goodness-offit test for the multiple logistic regression models," Communications in Statistics, vol. 10, pp. 1043-1069, 1980.

[25] S. Lemeshow and D. W. Hosmer, "The use of goodness-of-fit statistics in the development of logistic regression models," American Journal of Epidemiology, vol. 115, pp. 92-106, 1982.

[26] P. Dašić, "Algorithm approach to determination of reliability of components technical systems," in Proceedings of the 5th International Conference Research and Development in Mechanical Industy, pp. 34-45, Vrnjačka Banja, Serbia, 2005.

[27] P. Dašić, "Determination of reliability of ceramic cutting tools on the basis of comparative analysis of different functions distribution," International Journal of Quality and Reliability Management, vol. 18, no. 4, pp. 431-443, 2001.

[28] P. Dašić, A. Natsis, and G. Petropoulos, "Models of reliability for cutting tools: examples in manufacturing and agricultural engineering," Strojniški Vestnik/Journal of Mechanical Engineering, vol. 54, no. 2, pp. 122-130, 2008.

[29] C. R. Rao, Linear Statistical Inference and Its Applications, John Wiley \& Sons, New York, NY, USA, 2nd edition, 1973.

[30] J. F. Hair, W. C. Black, B. J. Babin, and R. E. Anderson, Multivariate Data Analysis, Pearson Prentice Hall, Upper Saddle River, NJ, USA, 7th edition, 2009.

[31] B. G. Tabachnick and L. S. Fidell, Using Multivariate Statistics, Pearson Education, Boston, Mass, USA, 6th edition, 2013.

[32] L. R. Ott and M. Longnecker, An Introduction to Statistical Methods and Data Analysis, Brooks/Cole, Belmont, Canada, 6th edition, 2010.

[33] N. J. D. Nagelkerke, "A note on a general definition of the coefficient of determination," Biometrika, vol. 78, no. 3, pp. 691-692, 1991. 


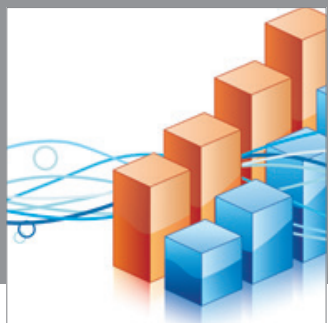

Advances in

Operations Research

mansans

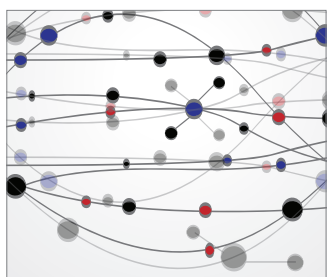

The Scientific World Journal
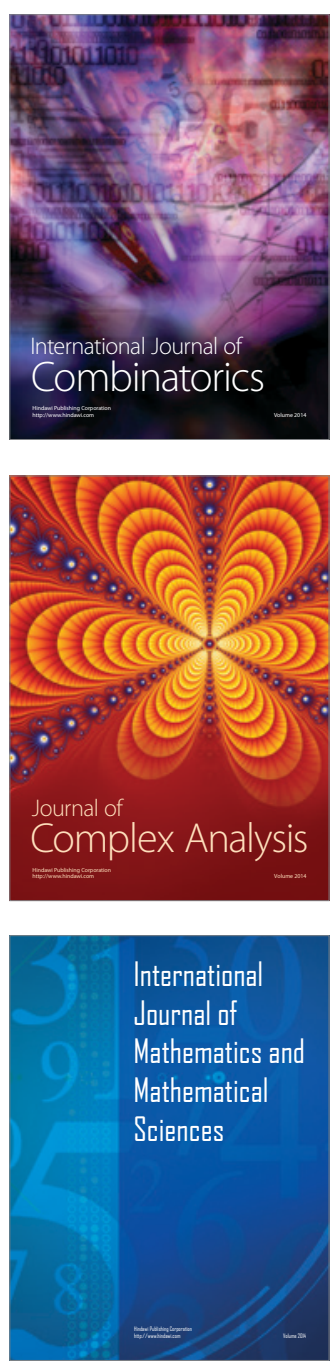
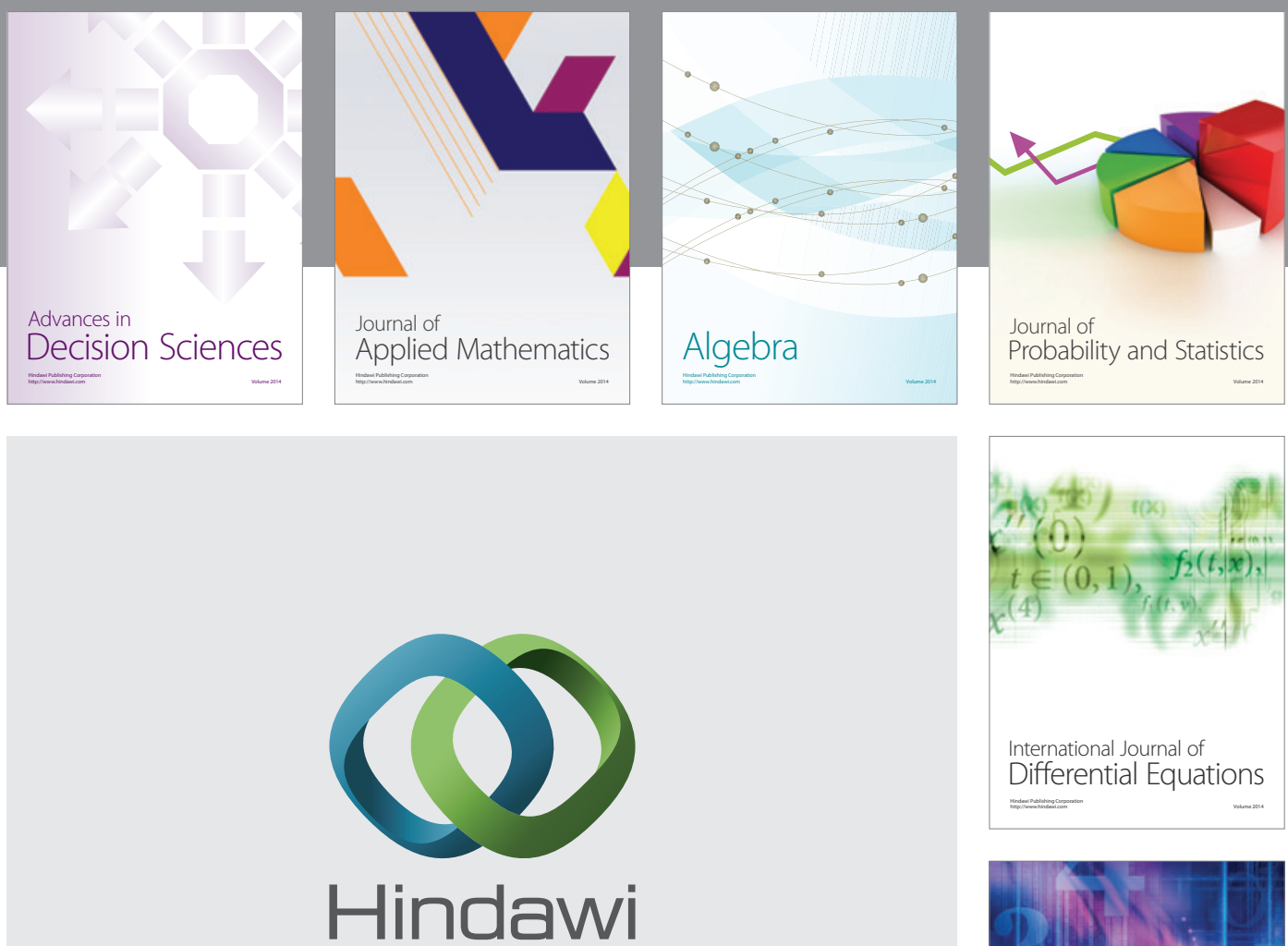

Submit your manuscripts at http://www.hindawi.com
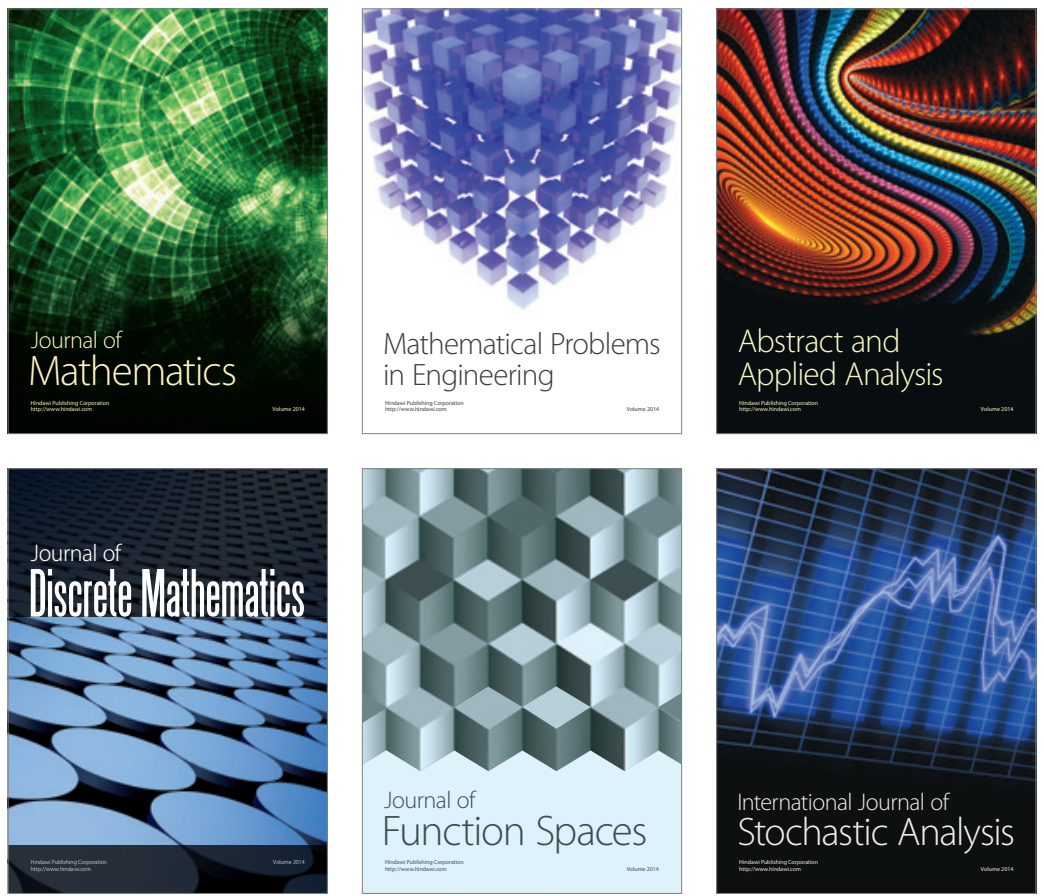

Journal of

Function Spaces

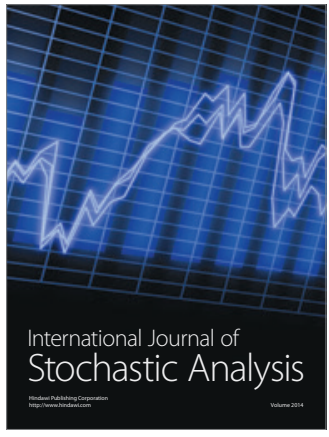

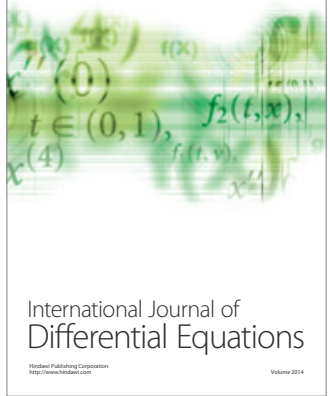
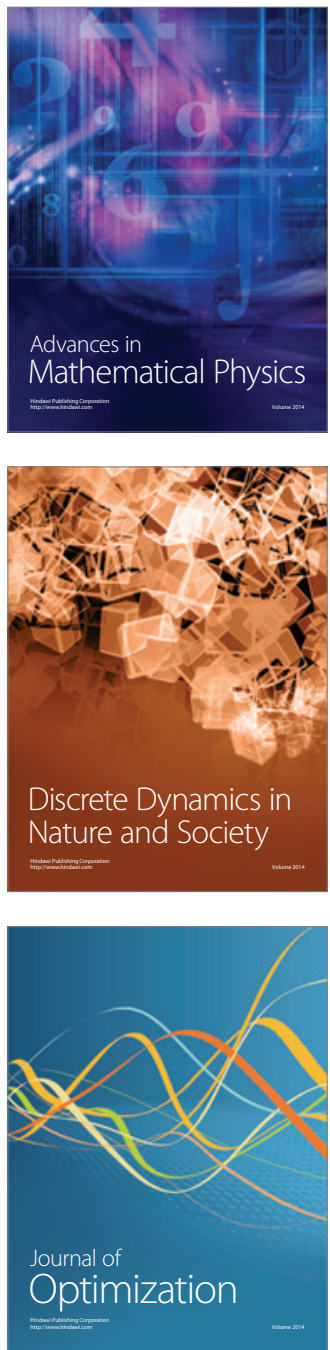